\title{
Evaluation of Different Thromboplastins and Coagulometers on International Normalize Ratio (INR) Readings for Patients under Stable Oral Anticoagulant Therapy
}

\author{
Rasha M. Ahmed ${ }^{1}$ and Abdel Rahim M. Muddathir ${ }^{2 *}$ \\ ${ }^{1}$ Department of hematology, Faculty of medical laboratory sciences, Alneelain University, Sudan \\ ${ }^{2}$ Department of Medical Laboratory Technology, Faculty of Applied Medical Sciences, Taibah University, Almadina Almunawarah, Kingdom Of Saudi Arabia \\ "Corresponding author: Abdel Rahim Mahmoud Muddathir, Department of Medical Laboratory Technology, Faculty of Applied Medical Sciences, Taibah University, \\ Almadina Almunawarah, P.O. Box 30001, Almadina Almunawarah, Kingdom Of Saudi Arabia, Tel: 00966531211398; E-mail: abdelrahimm@gmail.com
}

Received date: Aug 18, 2015, Accepted date: Oct 01, 2015, Publication date: Oct 05, 2015

Copyright: ( 2015 Ahmed RM, et al. This is an open-access article distributed under the terms of the Creative Commons Attribution License, which permits unrestricted use, distribution, and reproduction in any medium, provided the original author and source are credited.

\begin{abstract}
Background: Variations between various thromboplastin preparations have in the past led to decreased accuracy of INR readings. Because thromboplastin reagents vary widely in composition and manner of preparation, their sensitivity in monitoring oral anticoagulant therapy also vary widely. This study aimed to evaluate different thromboplastins and coagulometers on INR reading for patients under stable oral anticoagulant therapy.

Materials and Methods: This was descriptive cross-sectional study; it was conducted in three hospitals (Alshaab teaching hospital, Khartoum teaching hospital, and Turkish hospital). A total of 50 citrated platelets poor plasma samples were collected from 50 Sudanese patients under stable oral anticoagulant therapy then prothrombin time (PT) and INR measurements were performed on three separated laboratories, using different coagulometers and thromboplastins reagents.
\end{abstract}

Results: INR results showed that there was significant difference between INR of the three laboratories ( $P$ value $=0.00$ ), inspite of there was significant difference observed between INR in Khartoum hospital and Alshaab hospital, also between Alshaab and Turkish hospital $(p$-value $=0.00)$. There was insignificant difference between INR in Khartoum hospital and Trukish hospital ( $p$-value $=0.178)$.

Discussion and Conclusion: our investigation showed that some further efforts are needed to achieve harmonization of INR results among different laboratories because variation would most probably induce the clinician to make a change in warfarin dose. Standardization of instruments, reagents, and controls is warranted to decrease this variation.

Keywords: Thromboplastin; ISI; INR; Prothrombin time

\section{Abbreviation:}

ISI: International Sensitivity Index; PT: Prothrombin Time; MNPT: Mean Normal Prothrombin Time; AVK: Anti-Vitamin K Dependent Factor; PPP: Platelets Poor Plasma

\section{Introduction}

In 1983, the World Health Organization (WHO) adopted a method to establish consistency of the PT value for patient on AVK [1-3]. This mathematical expression of the PT value is termed INR [4]. The INR system has been developed to compensate for the major source of discrepancy in the prothrombin time assay, namely, the noticeable variation of response of thromboplastins to the change of vitamin $\mathrm{K}$ dependant clotting factors when a patient is undergoing anticoagulant treatment. While the INR method of reporting prothrombin time is now standard practice in many countries, efforts to introduce the INR system in North American Laboratories have had limited success so far [5]. Variations between various thromboplastin preparations have in the past led to decreased accuracy of INR readings, and a study suggested that despite international calibration efforts (by INR) there were still statistically significant differences between various kits [6]. Harmonization of results from different laboratories remains challenging [7]. Different types and sensitivities of thromboplastins [5] and interactions between thromboplastins and coagulation factors of individual patients may influence the accuracy of the instruments [8-10].

\section{Materials and Methods}

To evaluate different thromboplastins and coagulometers on INR reading for patients under stable oral anticoagulant therapy, a total of 50 plasma samples were collected and tested for PT/INR measurement.

A total of $1.8 \mathrm{ml}$ of venous blood was drawn by a practiced phlebotomist on vacutainer tube that contained $2 \mathrm{ml}$ of $3.2 \%$ (109 $\mathrm{mol} / \mathrm{L}$ ) sodium citrate without using tourniquet, then platelet poor plasma (PPP), was prepared by centrifugation of the citrated blood samples at $4000 \mathrm{rpm}$ for 15 minute. Plasma for each sample was divided into 3 containers then tested within 4 hours after collection by three separate laboratories in different hospitals (Alshaab teaching hospital, kahrtoum hospital and Turkish hospital) using different automated coagulometers (Sysmex CA-5, STAGO and HOSPTELEX). 
Page 2 of 3

Different thromboplastin reagents from rabbit brain origin with different ISI were used, including Fortress ISI (1.2), made in United Kingdom ,the second was Technoplastin HIS reagent ISI (1.08), made in Vienna and the third one was Spinreact reagent ISI (1.24), made in Spain.

In Alshaab hospital, PT/INR estimated by (Sysmex CA-50) coagulometer, using Fortress ISI (1.2), while in Turkish hospital was estimated by HOSPTELEX instrument, using Spinreact reagent ISI (1.24) and in Khartoum hospital was estimated by STAGO coagulometer using Fortress reagent ISI (1.2). The control plasma is obtained from 20 apparently healthy employees of normal males and females whom not pregnant and not under oral contraceptive bills, with no history of liver disease or coagulation disease and alcoholism.

For checking the quality control of the three coagulometers before testing the patients and normal controls for PT, commercial control TECLOT plasma (made in Germany) was used. Normal control readings ranged (11-17.3 seconds) and abnormal control (24.1-38.7 seconds). After controls tested, all the three instruments values were in the control range. Each test of patient and the prepared control was performed in duplicate, and then the average was calculated.

Data have been collected and analyzed by SPSS version 13.ANOVA test was used for calculating the significant difference.

\section{Results}

A total of 50 citrated blood samples collected from patients treated under stable oral anticoagulant therapy their age ranged (28-56) years with a mean of 42 years. Prepared platelets poor plasma was tested for PT using three different laboratories to evaluate different thromboplastins and coagulometers on patients INR readings.

Mean, standard deviation (SD) and ranges of INR in Alshaab teaching hospital were $(2.35,0.6,1.5$ to 4.4$)$ respectively and in Kahrtoum hospital $(2.81,0.321 .6$ to 3.8$)$,while in Turkish hospital $(2.98,0.67,1.9$ to 4.8$)$ respectively as shown in Table 1 .

When ANOVA test appied, INR results showed that there was significant difference between INR of the three laboratories ( $P$ value $=0.00$ ), and there was significant difference between INR in Khartoum hospital and Alshaab hospital, also between Alshaab and Turkish hospital ( $\mathrm{P}$ value $=0.00$ ). In spite of the observed difference in INR readings in Khartoum and Turkish hospital, there was no statistical difference obtained in INR ( $\mathrm{p}$-value $=0.178$ ), both hospitals used the same technology on their coagulometers machine (Mechanical clot-detection-based analyzer).

Most of PT and INR results showed lower reading when measured at A lshaab hospital than those of other two laboratories.

\begin{tabular}{|l|l|l|l|}
\hline & Alshab teaching hospital & Kahrtoum hospital & Turkish \\
\hline Mean & 2.35 & 2.81 & 2.98 \\
\hline SD & 0.6 & 0.32 & 0.67 \\
\hline Range & 1.5 to 4.4 & 1.6 to 3.8 & 1.9 to 4.8 \\
\hline
\end{tabular}

Table 1: Mean, SD and Range of INR on three labs.

\section{Discussion}

Harmonization of PT results and therapeutic ranges globally is an important goal. The introduction and recommendation of INR units were intended to serve this end [11]. The present study demonstrated that testing of PTand INR in separate laboratories, by different instruments and reagents, might occasionally generate misleading clinical information. In our study, The statistically significant differences were observed when plasma samples from patients who receiving warfarin were tested for INR on three different Laboratories, which was agreed with study done by Fitzmaurice et al. in which they compared the (INR) measurement in hospital and general practice settings, they found that there were significant differences between all hospital systems $P$ value less than 0.05 [1].

On other hand we observed that Laboratories mean PT results were differed from each other's which could be effect on patients' INR results. And this also agreed with study done by Brion Hurley et al. who stated that looking at the INR equation, the impact on INR results seemed to be more highly affected by mean of PT differences than ISI differences [12].

Also our finding agreed with their study in which they Used Lean Six Sigma ${ }^{\circ}$ Tools to Compare INR Measurements from Different Laboratories within a Community, and they found that Results showed a statistically significant difference among labs [12].

Also we observed that the electromechnical instrument which used at Khartoum $\mathrm{H}$ and Trukish $\mathrm{H}$ gived high reading of PT and INR results (of the same sample) than the photoptical instrument which used at Alshaab $\mathrm{H}$.

\section{Conclusion}

The study showed that some further efforts are needed to achieve harmonization of INR results among different laboratories because variation would most probably induce the clinician to make a change in warfarin dose. In addition to the standardization of instruments, reagents, and controls is warranted to decrease this variation.

\section{References}

1. Horsti J, Uppa H, Vilpo JA (2005) Poor agreement among prothrombin time international normalized ratio methods: comparison of seven commercial reagents. Clin Chem 51: 553-560.

2. Hirsh J, Fuster V, Ansell J, Halperin JL (2003) Guide to warfarin therapy. American Heart Association/American College of Cardiology Foundation Circulation.

3. Poller L (2004) International Normalized Ratios (INR): the first 20 years. J Thromb Haemost 2: 849-860.

4. Wayne PA (2008) One stage Prothrombin Time (PT) Test and Activated Partial Thromboplastin Time (APTT) Test; Approved Guideline. Clinical and laboratory stander institute (CLSI).

5. Ansell JE (1992) Imprecision of prothrombin time monitoring of oral anticoagulation. A survey of hospital laboratories. Am J Clin Pathol 98: 237-239. 
Citation: $\quad$ Ahmed RM, Muddathir ARM (2015) Evaluation of Different Thromboplastins and Coagulometers on International Normalize Ratio (INR) Readings for Patients under Stable Oral Anticoagulant Therapy. J Blood Disord Transfus 6: 313. doi:10.4172/2155-9864.1000313

Page 3 of 3

6. WHO Expert Biological Standardization (1999) Guidelines for thromboplastins and plasma used to control oral anticoagulant therapy. World Health Organization Tech Rep Ser: 889.

7. Attermann J (2003) Inaccuracy of international normalized ratio (INR) measurements and suggestions for improved WHO guidelines for calibration of reference preparations; a statistical study. J Thromb Haemost 1: 537-544.

8. Testa S, Morstabilini G, Fattorini A, Galli L, Denti N, et al. (2002) Discrepant sensitivity of thromboplastin reagents to clotting factor levels explored by the prothrombin time in patients on stable oral anticoagulant treatment: impact on the international normalized ratio system. Haematologica 87:1265-1273.

9. Jackson CM, Esnouf MP, Lindahl TL (2003) A critical evaluation of the prothrombin time for monitoring oral anticoagulant therapy. Pathophysiol Haemost Thromb 33: 43-51.
10. van den Besselaar AM (1996) Precision and accuracy of the international normalized ratio in oral anticoagulant control. Haemostasis 26 Suppl 4: 248-265.

11. Fitzmaurice DA, Murray ET, Allan TF, Holder RL, Rose PE, et al. (2000) A comparison of international normalised ratio (INR) measurement in hospital and general practice settings: evidence for lack of standardization. J Clin Pathol 53: 803-804.

12. Authors Hurley B, Levett JM, Huber C, Taylor TL (2008) Using Lean Six Sigma ${ }^{\star}$ Tools to Compare INR Measurements from Different Laboratories Within a Community. Using Lean Six Sigma Tools to Compare INR Measurements from Different Laboratories Within a Community. 